\title{
ON THE INTERSECTIONS OF CONES AND SUBSPACES ${ }^{1}$
}

\author{
BY A. BEN-ISRAEL AND A. CHARNES
}

Communicated by L. Cesari, January 2, 1968

Introduction. Farkas' theorem [9], basic to the theory of linear inequalities (e.g. [15], [7]) and its applications (e.g. [6]), was extended to linear topological spaces in [11], [8], [3], [4], using the separation of closed convex cones and points outside them. In this note a separation argument is used to prove a theorem on the intersections of cones and subspaces in locally convex spaces, which in the finite dimensional case reduces to Farkas' theorem. This approach is similar to that in [1], [13] and [14].

Notations. Let $E$ be a locally convex real linear topological space, $E^{*}$ the space of continuous linear functionals on $E$. For any subset $S$ of $E$ let

$\operatorname{cl}(S)$ denote the closure of $S, S^{*}=\left\{x^{*}: x^{*} \in E^{*}, x^{*}(x) \geqq 0, x \in S\right\}$.

Similarly for a subset $S^{*}$ of $E^{*}$ let

$$
*\left(S^{*}\right)=\left\{x: x \in E, x^{*}(x) \geqq 0, x^{*} \in S^{*}\right\} .
$$

If $L \subset E$ is a subspace

$$
L^{*}=L^{0}=\left\{x^{*}: x^{*} \in E^{*}, x^{*}(x)=0, x \in L\right\}
$$

and for a subspace $L^{*}$ of $E^{*}$

$$
{ }^{*}\left(L^{*}\right)={ }^{0}\left(L^{*}\right)=\left\{x: x \in E, x^{*}(x)=0, x^{*} \in L^{*}\right\} .
$$

TheOREM. Let $E$ be a locally convex real linear topological space, $L$ a closed linear subspace in $E, C$ a closed convex cone in $E$. Then

$$
{ }^{*}\left(L^{0} \cap C^{*}\right)=\operatorname{cl}(L+C) \text {. }
$$

Proof. Clearly $\mathrm{cl}(L+C) C^{*}\left(L^{0} \cap C^{*}\right)$.

Conversely suppose there is an $x_{0}$ such that $x_{0} \in{ }^{*}\left(L^{0} \cap C^{*}\right)$, $x_{0} \notin \operatorname{cl}(L+C)$. The last fact implies that the convex compact set $\left\{x_{0}\right\}$ can be strictly separated from the closed convex $\operatorname{set} \operatorname{cl}(L+C)$, e.g. $\left[5\right.$, p. 73]. Thus there is a $y^{*} \in E^{*}$ such that $y^{*}(\operatorname{cl}(L+C)) \geqq 0$,

1 This research was partly supported by the National Science Foundation, Project GP 7550, and by the Office of Naval Research, Contract Nonr-1228(10), Project NR 047-021, and by the U. S. Army Research Office-Durham, Contract No. DA-31-124ARO-D-322, at Northwestern University. Reproduction of this paper in whole or in part is permitted for any purpose of the United States Government. 
$y^{*}\left(x_{0}\right)<0$. From $y^{*}(\operatorname{cl}(L+C)) \geqq 0$ it follows that $y^{*} \in L^{0}$ and therefore $y^{*} \in C^{*}$. Therefore $y^{*} \in L^{0} \cap C^{*}$ and $y^{*}\left(x_{0}\right)<0$ contradicts $x_{0}$ $\in^{*}\left(L^{0} \cap C^{*}\right)$.

Q.E.D.

Corollary 1. Let $E, F$ be real normed linear spaces, $T: E \rightarrow F$, a continuous linear operator such that its conjugate $T^{\prime}: F^{*} \rightarrow E^{*}$ satisfies

$$
\left({ }^{0} \mathrm{cl}\left(R\left(T^{\prime}\right)\right)\right)^{0}=\mathrm{cl}\left(R\left(T^{\prime}\right)\right) .
$$

Let $C$ be a closed convex cone in $E$ and $f \in F$ be such that the equation

$$
T x=f \quad \text { is solvable. }
$$

Then there is a sequence $\left\{x_{k}\right\}$ in $C$ such that

$$
\lim _{x \rightarrow \infty} T x_{k}=f
$$

if and only if for any solution $x_{0}$ of (3) and any point $x^{*}$ in $\operatorname{cl}\left(R\left(T^{\prime}\right)\right)$ :

$$
x^{*} \in C^{*} \text { implies } x^{*}\left(x_{0}\right) \geqq 0 .
$$

Proof. A sequence $\left\{x_{k}\right\}$ in $C$ for which (4) holds exists if and only if for any solution $x_{0}$ of (3)

$$
x_{0} \in \operatorname{cl}(N(T)+C) \text { or } x_{0} \in{ }^{*}\left(N(T)^{0} \cap C^{*}\right) \text { by (1). }
$$

From (2) it follows that $N(T)^{0}=\mathrm{cl}\left(R\left(T^{\prime}\right)\right.$ ), e.g. $[17$, p. 226] so that (6) gives: $x_{0} \in^{*}\left(\mathrm{cl}\left(R\left(T^{\prime}\right)\right) \cap C^{*}\right)$ which is (5). Q.E.D.

REMARK. (2) holds if $E$ is norm reflexive or if $R\left(T^{\prime}\right)$ is finite dimensional, e.g. [17, p. 227].

Corollary 2. Let $E, F$ be real Hilbert spaces, $T: E \rightarrow F$ a continuous linear operator, $T^{*}: F \rightarrow E$ its adjoint.

Let $C$ be a closed convex cone in $E$ and $f \in F$ be such that the equation

$$
T x=f \quad \text { is solvable. }
$$

Then there is a sequence $\left\{x_{k}\right\}$ in $C$ such that

$$
\lim _{x \rightarrow \infty} T x_{k}=f
$$

if and only if for any point $x^{*}$ in $\operatorname{cl}\left(R\left(T^{*}\right)\right) x^{*}=\lim _{k \rightarrow \infty} T^{*} y_{k}^{*}$

$$
x \in C^{*} \text { implies } \lim _{n \rightarrow \infty}\left(y_{n}^{*}, f\right) \geqq 0 .
$$

Proof. Follows from Corollary 1 by choosing $x_{0}=T^{+} f$, where $T^{+}$ is the generalized inverse of $T$, e.g. [16], [2]. Indeed the conclusion $x^{*}\left(x_{0}\right) \geqq 0$ of $(5)$ is rewritten as: 


$$
\begin{aligned}
0 \leqq x^{*}\left(x_{0}\right) & =\lim _{n} T^{*} y_{n}^{*}\left(T^{+} f\right), \\
& =\lim _{n}\left(y_{n}^{*}, T T^{4} f\right)=\lim _{n}\left(y_{n}^{*}, f\right),
\end{aligned}
$$

since $T T^{+}=P_{\mathrm{ol}(R(T))}$, e.g. [2] and $f \in R(T)$. Q.E.D.

REMARKs. (a) If $E, F$ are real finite dimensional spaces and $C=C^{*}$ is the nonnegative orthant in $E$, then Corollary 2 reduces to Farkas' theorem, e.g. [18], [10]:

$$
\begin{aligned}
& T x=f, x \geqq 0 \text { is solvable if and only if: } \\
& T^{T} y \geqq 0 \text { implies }(y, f) \geqq 0 .
\end{aligned}
$$

(b) The finite dimensional statement of Corollary 1 is:

Let $C$ be any closed convex cone in $R^{n}, A$ be an $m \times n$ matrix and $b \in R(A)$. Then there is a sequence $\left\{x_{k}\right\}$ in $C$ such that

$$
\lim _{k} A x_{k}=b
$$

if and only if

$$
A^{T} y \in C^{*} \quad \text { implies }(b, y) \geqq 0 \text {. }
$$

(c) In particular if $C$ is a polyhedral convex cone in $R^{n}$ then $N(A)$ $+C$ is closed and (11) is equivalent to

$$
A x=b, \quad x \in C,
$$

being solvable.

\section{REFERENCES}

1. A. Ben-Israel, Notes on linear inequalities. I, J. Math. Anal. Appl. 9 (1964), 303-314.

2. A. Ben-Israel and A. Charnes, Contributions to the theory of generalized inverses, J. Soc. Indust. Appl. Math. 11 (1963), 667-699.

3. C. C. Braunschweiger and H. E. Clark, An extension of the Farkas theorem, Amer. Math Monthly 69 (1962), 272-276.

4. C. C. Braunschweiger, An extension of the nonhomogeneous Farkas theorem, Amer. Math. Monthly 69 (1962), 969-975. 1953.

5. N. Bourbaki, Espaces vectoriels topologiques, Chapter I, II, Hermann, Paris,

6. A. Charnes and W. W. Cooper, Management models and industrial applications of linear programming, Vols. I, II, Wiley, New York, 1961.

7. K. Fan, "On systems of linear inequalities," pp. 99-156 in [12 ].

8. - Convex sets and their applications, Argonne National Laboratory Lecture notes, Argonne, Ill., summer 1959.

9. J. Farkas, Über die Theorie der einfachen Ungleichungen, J. Reine Angew. Math. 124 (1902), 1-24. 

[12].

10. A. J. Goldman and A. W. Tucker, "Polyhedral convex cones," pp. 19-40 in

11. L. Hurwicz, "Programming in linear spaces," Chapter 4 in: K. J. Arrow, L. Hurwicz and J. Uzawa, Studies in linear and nonlinear programming, Stanford Univ. Press, Stanford, Calif., 1958.

12. H. W. Kuhn and A. W. Tucker (Editors), Linear inequalities and related systems, Princeton Univ. Press, Princeton, N. J., 1956.

13. N. Levinson, Linear programming in complex space, J. Math. Anal. Appl. 14 (1966), 44-62.

14. N. Levinson and T. O. Sherman, The sum of the intersections of a cone with a linear subspace and of dual cone with orthogonal complementary subspace, J. Combinatorial Theor. 1 (1966), 338-349.

15. T. S. Motzkin, Beitrage zur Theorie der linearen Ungleichungen (Dissertation, Basel, 1933) Azriel, Jerusalem, 1936.

16. R. Penrose, $A$ generalized inverse for matrices, Proc. Cambridge Philos. Soc. 51 (1955), 406-413.

17. A. E. Taylor, Introduction to functional analysis, Wiley, New York, 1958.

18. A. W. Tucker, "Dual systems of homogeneous linear relations," pp. 3-18 in [12].

NORTHWESTERN UNIVERSITY 